\title{
El sentido filosófico de la vida en el pensamiento existencialista: Una lectura desde Ellacuría
}

Ronald Carrillo ${ }^{1}$

Recibido el 21 de septiembre de 2017, aceptado para su publicación el 20 de octubre de 2017

Si el ser humano privilegia la esencia sobre la existencia y suprime la libertad de elegir qué queremos ser, destruimos aquello que nos dota de sentido, quizá del único sentido

por el que merece

la pena vivir².

\begin{abstract}
Resumen
La pregunta por el sentido de la vida y la filosofía nacen al mismo tiempo en el mundo griego. La angustia que genera la finitud de la existencia humana es la que motiva al hombre a preguntarse por el sentido de la vida. El pensamiento existencialista retoma la cuestión del hombre y su existencia, volviendo a reflexionar sobre la libertad y la historia. Este trabajo busca identificar los conceptos relacionados con el sentido de la vida en el pensamiento existencialista aplicando el método de historización. La tesis central en este escrito es que dichos conceptos influyen en la filosofía de Ellacuría permitiéndole proponer al ser humano histórico como fundamento filosófico del sentido de la vida.
\end{abstract}

\section{Palabras clave}

Ser humano, existencia, angustia, muerte, libertad, historia, proyecto, sentido de vida.

\section{Abstract}

The question of the meaning of life and philosophy is born at the same time in the Greek world. The anguish generated by the finitude of human existence is what motivates man to ask about the meaning of life. Existentialist thinking retakes the question of man and his existence, returning to reflect on freedom and history. This work seeks to identify the concepts related to the meaning of life in existentialist thinking applying the method of historization. The central thesis in this writing is that these

1. Ronald Gilberto Carrillo Salvador, Master en Filosofía, rcarrillo@ups.edu.ec,

2. Francis Fernandez, «Sartre y el sentido de la vida». 
concepts influence the philosophy of Ellacuría allowing him to propose to the historical human being as a philosophical foundation of the meaning of life.

\section{Key Words}

Human being, existence, anguish, death, freedom, history, project, meaning of life.

\section{Introducción}

En palabras de Marcel "en un mundo donde lo funcional triunfa en todos los planos el sentido del ser queda inevitablemente suprimido" es decir, en el momento actual la sociedad urbana occidental vive inmersa en un vértigo por funcionar, donde el tiempo se invierte en cumplir con tareas laborales de tipo económico y material. No hay momento ni espacio para la reflexión, solo para la acción encaminada a lograr el sustento diario, sobrevivir. En este contexto, la reflexión sobre el sentido de la vida queda reducida a los ámbitos académicos e intelectuales, por ello este trabajo propone retomar la pregunta sobre el sentido de la vida y presentar con un lenguaje asequible para el ciudadano común una aproximación lo que propone el pensamiento de tres existencialistas, identificar los conceptos que utilizaron y confrontarlos con el pensamiento personalista de Ignacio Ellacuría, quien consideraba a la filosofía como una forma de vida, como la actividad reflexiva que lleva al filósofo a vivir cómo piensa y a pensar cómo vive. La propuesta ellacuriana, para responder a la cuestión sobre el sentido de la vida, parte de su insatisfacción con la filosofía medieval y de su apertura a las corrientes de pensamiento que le son contemporáneas, una de ellas el existencialismo. De esta última, Ellacuría tomará la visión antropológica para llegar a proponer al ser humano como histórico, es decir, el ser humano como protagonista de su existencia, aquel que hace historia con su historia.

\section{Características del pensamiento existencialista.}

La excesiva importancia dada a la razón, a raíz del planteamiento cartesiano, pienso luego existo, desemboca en el idealismo hegeliano que considera a la idea como la base para el conocimiento de la realidad porque para él la idea es la realidad efectiva. El pensamiento existencialista surge a finales del siglo XIX como una reacción frente al idealismo hegeliano y se desarrolla con fuerza en el siglo $X X$ donde plantea la preeminencia de la existencia sobre la esencia, es decir, que el ser humano primero existe y luego piensa.

La filosofía moderna fundamentó sus reflexiones en la razón y la metafísica, entendiendo al hombre como un sujeto que puede percibir el mundo objetivo, sin tomar en cuenta que la conciencia humana y la manera de entender el mundo es histórica y cultural, es decir, están condicionadas al momento y el lugar donde se 
desarrolla la vida del hombre. El pensamiento existencialista, al contrario, toma conciencia de que el ser humano está inmerso en el mundo y que primero debe partir de lo es para proyectarse hacia lo que quiere ser, en otras palabras, haczer filosofía es buscar el fundamento a la existencia, cuestionarse sobre el sentido de la vida.

Actualmente se reconoce en el pensamiento existencialista tres escuelas: la perspectiva cristiana (Kierkegaard, Marcel), la agnóstica (Heidegger, Camus) y la postura atea (Sartre).

Camus al inicio de su obra "el mito de Sísifo" afirma que: "No hay más que un problema filosófico verdaderamente serio: el suicidio. Juzgar si la vida vale o no vale la pena de vivirla es responder a la pregunta fundamental de la filosofía."3 Las dos grandes guerras mundiales llevaron a la humanidad a situaciones extremas y límite, donde el sin sentido de la vida se hizo patente en el horizonte de la filosofía, por lo que la opción de acabar con lo absurdo de la vida es un hecho que preocupa aún en el siglo XXI, convirtiéndose en un asunto de salud pública, especialmente en los adolescentes y jóvenes por cuanto fue la segunda causa de defunción en el grupo etario de 15 a 29 años a nivel mundial en el 2015 según la página web de la $\mathrm{OMS}^{4}$

\section{El pensamiento de tres existencialistas y Ellacuría}

Soren Kierkegaard, filósofo de origen danés, se opuso al pensamiento hegeliano, a la idea de que la realidad es lo que se piensa ya que reflexionó sobre la condición de la existencia humana y la búsqueda de un sentido a la vida: "Tengo que hallar una verdad para mí, encontrar esa idea por la que quiero vivir y morir"5 Esta afirmación es su declaración de ser un filósofo que está en búsqueda. El joven Ellacuría coincide con esta vocación del filósofo danés cuando, en 1954, escribe a su maestro Ángel Martínez "lo que trato es de buscar una base filosófica de mi posición ante la vida en el sentido de exigir una actitud vital de todo el hombre y recreadora". Ambos autores coinciden en que necesitan encontrar el fundamento filosófico que de sentido a su vida.

Los conceptos de desesperación, angustia y esperanza son muy importantes frente al misterio de la vida y Kierkegaard los va explicando a lo largo de su obra bibliográfica en donde se puede apreciar su manera de concebir la vida destacando tres actitudes que el ser humano puede adoptar: estética, ética y religiosa.

3. Albert Camus, El mito de Sísifo.

4. OMS, «Datos y cifras sobre el suicidio: infografía».

5. Kierkegaard, Soren Temor y temblor (Madrid: Editora Nacional, 1975) pág. 40

6. Ignacio Ellacuría, «Correspondencia con Ángel Martínez», 202. 
Kierkegaard proviene de una familia con una formación cristiana muy férrea. Su Padre era muy escrupuloso por lo que transmitió su temor al pecado y al castigo divino. La forma de concebir la culpa, hace reflexionar a Soren sobre la posibilidad de superar la angustia que provoca el pecado mediante el abandono a la voluntad de Dios (fe). "La angustia deviene de la puja interna -humana- entre lo terrenal y lo espiritual. El hombre adquiere el concepto de infinitud (divinidad) pero sigue siendo a la vez mortal, terreno"7. En su juventud vivió el dilema de optar por la vida religiosa o la vida en pareja. Se enamoró de Regina Olsen, pero por su formación, entiende que es la tentación que le impide seguir el camino que Dios tiene para él. Por eso abandona su relación con ella y opta -como Abraham- por sacrificar lo que más amaba en la vida para ser fiel a su idea de voluntad de Dios:

\begin{abstract}
"Desde ese momento se genera en Kierkegaard una desesperación y una angustia, que es propia de cualquier ser humano que no sabe qué hacer con su vida, que se encuentra en una encrucijada, por un lado quiere caer en la tentación y enamorarse y ser "feliz" pero por otro lado está el mandato que le impusieron de no caer en la tentación, de hacer la voluntad de Dios”8
\end{abstract}

Esta opción de la esperanza que implica la superación de la desesperación y la angustia mediante el salto de fe, es el camino que Kierkegaard propone para orientar la vida del ser humano, que se debate entre adoptar una actitud estética, ética o religiosa ante la realidad de la muerte.

Para Kierkegaard, el esteta es el que se preocupa de los asuntos triviales, de vivir el día a día de manera sensual, pero al final del día se siente vacío pues los placeres que se presentan en la cotidianidad son pasajeros, son emociones que se agotan al instante. Esta situación es lo que Kierkegaard denomina el estadio estético como una forma de vida que está presente en todas las personas cuando se dejan llevar por lo superfluo: define al esteta como aquel que vive en la superficialidad sensual y el placer. Quien vive así evita a toda costa lo que signifique sufrimiento o dolor. Se aparta de las experiencias no placenteras creyendo que la felicidad radica en fugarse de la realidad personal y crear un mundo ficticio donde lo sensual es lo primordial. Se vive el momento, se busca la emoción, la intensidad fugaz de un instante de pasión y de goce sensual. Esta clase de vida se convierte en la droga anhelada, la que permite no enfrentar la realidad personal, evadiendo cualquier responsabilidad. Las decisiones del esteta son volubles, variables, mutan en cualquier momento pues se deja llevar por lo que le signifique alcanzar más placer. No ancla sus decisiones en los valores éticos.

7. Ramírez César El retorno al ser, una propuesta frente al sinsentido (Medellín: Universidad Pontificia Bolivariana, 2014) pág. 31

8. Ibid pág. 32 
El esteta no se preocupa por sí mismo, se deja llevar por la necesidad sensual, es un esclavo del destino. Sin libertad no necesita crecer, ya es lo que las situaciones le hacen ser. Su vida no se dirige a ninguna meta, ya llegó, es un círculo vicioso del cual no escapa, se disuelve en la diversión. Modelos de este tipo de vida son: Don Juan Tenorio, Fausto y el Judío errante.

El personaje de Zorrilla, Don Juan Tenorio es el "picaflor" que disfruta conquistando a las mujeres pero que no llega a comprometerse y establecer un proyecto con ninguna de ellas. El personaje Fausto de la novela de Goethe es el esteta intelectual, perdido en el mundo de las ideas y que goza de la literatura, pero que ninguna le provoca confrontación ni compromiso, es un lector pasivo, un espectador del conocimiento que se conforma con apreciar pero que no se compromete con nada ni con nadie. En el extremo de la vida esteta está el mítico Judío Errante a quién Jesús condenó por negarle agua para calmar su sed en el camino al calvario. Su condena consiste justamente en seguir vivo como errante hasta la vuelta de Jesús. Es un hombre estético, porque no puede morir, ni descansar. Su vida es de total insatisfacción, está asqueado del mundo y condenado a nunca alcanzar el gozo y la paz.

Esta situación de existencia estética conduce a la desesperación a la que Kierkegaard llama enfermedad mortal. La desesperación, es lo contrario a la esperanza, es el escenario que enfrenta quien ha perdido la esperanza, quien lo ha perdido todo y no le queda nada que esperar. El desesperado tiene dos opciones, la primera es sobrevivir en el mundo, diluirse en las actividades diarias que le hacen olvidar momentáneamente su realidad; la segunda es optar por algo distinto, por cambiar la realidad sin huir de ella. En este contexto, la desesperación puede empujar al ser humano hacia el estadio ético. Por eso Kierkegaard aconseja a quien desespera:

\footnotetext{
“Elige la desesperación. La desesperación misma es una elección, ya que se puede dudar sin elegir, pero no se puede desesperar sin elegir. Desesperándose uno se elige de nuevo, se elige a sí mismo, no en la propia inmediatez, como individuo accidental, sino que se elige a sí mismo en la propia validez eterna."
}

Eligiéndose a sí mismo en su propia validez eterna el hombre entra en contacto con lo general, encontrándose con lo total. Es a la vez un acto de renuncia a ser una excepción, una particularidad, como un acto de voluntad para tomar la decisión de salir de la desesperación y adquirir la estabilidad que le brinda una vida ética fundada en los valores universales. 
En su obra el concepto de la angustia, Kierkegaard reflexiona sobre el significado de la angustia y la expone como:

\begin{abstract}
“La angustia es el vértigo de la libertad, un vértigo que surge cuando la libertad echa la vista hacia abajo por los derroteros de su propia posibilidad, aferrándose a la finitud para sostenerse... En ese vértigo la libertad cae desmayada y cuando se incorpora de nuevo ve que es culpable."10
\end{abstract}

El autor, aborda el tema desde la perspectiva creyente, por eso menciona que la angustia se relaciona con la libertad, pero esa libertad que se siente culpable porque el ser humano busca la rectitud, lo correcto de manera libre apartándose de lo que considera culpa, ya que si se hiciera culpable no sería libre. Pero la realidad de los hombres es que no siempre actuamos correctamente a pesar de hacerlo con libertad y eso nos angustia. La gente teme hacer uso de su libertad por cuanto es más fácil obedecer lo que las autoridades demandan, pero cuando nos enfrentamos a la libertad de actuar, sentimos temor de equivocarnos, de hacer lo que no queríamos, de caer y por tanto de culpabilizarnos.

El hombre ético es el que conoce y vive la diferencia entre el bien y el mal de manera absoluta. Organiza su vida y la ordena minuciosamente para cumplir con el deber. Respeta la moral establecida. Renuncia a ser un individuo en particular propenso a la equivocación. El hombre ético se hace con sus opciones libres, se construye, llega a ser algo nuevo, por eso tiene un proyecto, respeta la palabra empeñada, toma decisiones. Es el tipo que opta y luego reafirma sus opciones en la repetición volviéndolas hábito. Ejemplo de este tipo de vida es el esposo o la esposa, que no sólo se eligen al momento de contraer matrimonio, sino que día a día repiten esa opción, la confirman, viviendo en fidelidad a sus votos esponsales. Para el hombre ético, la angustia se genera en el día a día por cuanto busca cumplir con su responsabilidad, no fallar, ser recto y justo. La angustia vive con él, está presente en sus actos porque se siente frágil, finito, tentado. Es el hombre que repite una y mil veces cuando ora la parte final del Padre Nuestro "no nos dejes caer en la tentación y líbranos del mal".

Kierkegaard en su obra El concepto de la angustia plantea que "el hombre es ese ser que se angustia y, cuanto más profundamente se angustia, tanto más grandioso es el hombre"11. Esta angustia conmina al ser humano a buscar una salida, una posibilidad, una esperanza que necesariamente está más allá de sus limitaciones y lo proyecta hacia lo infinito, lo inmutable, lo trascendente que es lo que Soren llama el salto desesperado de la fe, el salto a la existencia religiosa.

10. Kierkegaard El concepto de la angustia traducción y prólogo de Demetrio Gutiérrez Rivero (Madrid: Alianza Editorial, 2007) pág. 118

11. Soren Kierkegaard, «El concepto de la angustia», 261. 
El hombre religioso es el que, por la fe, cambia la desesperación por esperanza y la angustia por confianza en la providencia de Dios. Vive en la presencia de Dios. Ama a Dios como primera determinación y por eso no quiere ofenderlo. Sabe que su deber absoluto no es cumplir con la ley sino someterse a la voluntad de Dios. Si Dios le pide algo excepcional, incluso algo que contraríe la ley, algo que plantee una excepción a la norma general, él responde, aunque no llegue a entender por qué Dios le pide semejante cosa. El modelo de hombre de fe que es Abraham lo encontramos bien descrito en la obra Temor y temblor. "El Padre de la Fe" como es conocido tuvo que cumplir con la exigencia de sacrificar a su pequeño y único hijo de la promesa, Isaac. Abraham, en contra de toda lógica y en contra de sus propios sentimientos paternales, estuvo a punto de matar a su hijo, con tal de complacer a Dios. El hombre religioso obra por amor, no actúa por temor, ni por deber u obligación, por lo que el hombre religioso se posiciona por encima de la ley, en consecuencia queda liberado de la obligatoriedad.

Como se puede ver, para Kierkegaard, el ser humano debe andar el camino, tal y como lo propone Machado "caminante no hay camino, se hace camino al andar". Tiene que ponerse en pie y asumirse a pesar de descubrirse como un ser inestable que migra de un estadio a otro. El hombre religioso es el que a fin de cuentas debe imponerse, superar la desesperación y la angustia, dando sentido a su existencia porque "el hombre existe porque se acepta a sí mismo como existente que dura, el hombre se elige a sí mismo como existente. Y sí se niega a elegirse a sí mismo estará eligiendo como quien elige no querer elegirse"12

Kierkegaard hace de la vida una terrible aventura de lo absurdo, en donde la desesperación y la angustia hacen del ser humano un ser sin rumbo que solamente puede ver la luz en su abandono en Dios, en confiar infinitamente en que la fe lo va a salvar. Cuando Hegel afirma que lo real es racional y lo racional es real, Kierkegaard se atreve a postular que lo personal es lo real, porque la autenticidad del ser humano radica en ser el mismo, en elegirse a sí mismo donde su mejor tarjeta de presentación es el hombre en estado religioso.

Ellacuría, si bien no menciona a Kierkegaard en sus escritos, coincide con su pensamiento cuando hace un análisis de la situación histórica que le ha tocado vivir:

\footnotetext{
"Basta con observar nuestro tiempo, para vernos a nosotros por dentro como hombres de nuestro tiempo, para vernos como lanzados a la irreligiosidad, al olvido vital de Dios, de modo que nuestro esfuerzo tiene que ejercitarse en ser religiosos y no en lo contrario." ${ }^{3}$
}

12. Kierkegaard Mi punto de vista (Buenos Aires: Biblioteca de Iniciación filosófica Aguilar, 1959), 40. 13. Ignacio Ellacuría, «Sobre la irreligiosidad», 273. 
El filósofo vasco propone la vuelta a la fe, confrontando al ateísmo que cada vez gana más adeptos a finales del siglo XX, pues “La religión, en efecto, como forma de vida, es decir, como religiosidad, implica una actitud de la vida entera respecto de Dios"14 por lo que el ser humano solo es posible si está ligado a Dios, ya que dice Ellacuría que el ser del hombre es lo que es por lo que ha recibido de Dios, pero que ese ser que Dios ha dado al hombre es un ser histórico, libre para hacerse, para realizarse. Aquí Ellacuría expone la natural apertura del hombre a la trascendencia, ya que considera al ser humano una creatura de Dios que debe reconciliar su existencia vital con su esencia religiosa en el momento histórico que le toca vivir.

Martín Heidegger (1889 - 1976) nació en Messkirch, Alemania y es considerado como uno de los filósofos más importantes del siglo XX. Su filosofía tuvo la influencia de Kierkegaard, Nietzsche y de Husserl quién fue su profesor. Fue catedrático de filosofía y rector en la Universidad de Friburgo (1933). Su apoyo intelectual al nazismo inicial le mereció duras críticas y fue causa para que los aliados lo destituyeran de la cátedra (1945). Se reincorporó seis años después como docente honorario.

Su obra Ser y tiempo, escrita en 1927, es un libro que impactó en sus contemporáneos y en los existencialistas posteriores como Sartre, Camus. Al Heidegger de Ser y tiempo se le conoce como el primer Heidegger porque en esta etapa de su vida, su pensamiento parte de la pregunta ¿por qué hay algo y no más bien nada? ya que lo que constatamos en la vida cotidiana es que hay cosas. Para este autor, es necesario reflexionar sobre el ser ya lo que hay es ser y por eso la filosofía debe ocuparse de la pregunta por el ser:

Pero podría desearse también saber para qué ha de servir esta pregunta. ¿Se queda ella en una pura especulación en el aire sobre las más universales generalidades? ¿Es tan sólo eso? ¿O es, por el contrario, la pregunta más fundamental y a la vez la más concreta? ${ }^{15}$

La pregunta por el ser se convierte en Heidegger en el punto de partida para "Ser y tiempo". En principio su texto parecería una obra ontológica que se ocupa del ser pero según se va adentrando en su lectura se descubre que es un libro existencial, un texto antropológico, ya que es una reflexión sobre el ente pero cambiando la pregunta de ¿qué es el ser?, por la de ¿quién se pregunta por el ser? En este punto se cuestiona sobre cómo viene al mundo la pregunta por el ser; entonces manifiesta que existe un ser capaz de cuestionarse por el ser, por eso rompe con las teorías gnoseológicas que planteaban la posibilidad de un sujeto capaz de conocer los objetos porque se encontraba a distancia de ellos. Heidegger en su obra aborda la pregunta por el ser, pero da un giro al replantear

14. Ibid., 272.

15. Martín Heidegger, Ser y tiempo, 19. 
la pregunta y exponerla como ¿quién es el ser capaz de preguntarse por el ser? Ante este nuevo cuestionamiento, propone el Dasein, término compuesto por dos palabras alemanas: Da que se traduce como ahí, y sein traducido como ser. Entonces el Dasein es el ser ahí, arrojado al mundo, el que tiene como constitución fundamental el estar-en-el-mundo. El ser que se pregunta por el ser es el Dasein que en Heidegger es el hombre. "A este ente que somos en cada caso nosotros mismos, y que, entre otras cosas, tiene la posibilidad de ser que es el preguntar, lo designamos con el término Dasein"16.

Ellacuría dirá que "Cuando Heidegger llama temáticamente al existir humano DaSein, quiere recalcar que lo realmente importante en el hombre es la presencia del ser; el hombre es en sí mismo una determinada presencia del ser, y sólo desde esta presencia es el hombre lo que es"17, es decir recurre al concepto heideggeriano para proponer que es el hombre.

Pero quién es este Dasein para Heidegger; en la primera parte de Ser y tiempo, en su primera sección, Heidegger desarrolla una etapa preparatoria del análisis fundamental del Dasein y ahí es cuando afirma que es el hombre caído, arrojado, eyectado en el mundo, el que está en el mundo, angustiado ante la presencia de la nada, que siente su finitud y lo inminente de la muerte. Ellacuría afirma que "Lo que en Heidegger es la ontología fundamental como análisis ontológico del Dasein análisis existencial, en Zubiri es análisis metafísico de la realidad, análisis esencial."18, es decir se vuelve a la cuestión de la esencia del hombre que para Ellacuría es un asunto preontológico. Esa esencia que ya viene dada, no significa que está realizada de manera plena, le corresponde al hombre llevarla a su realización.

Heidegger en su análisis del Dasein continua diciendo cuál es su sentido teleológico: "El "fin" del estar-en-el- mundo es la muerte"19. Es el ser que sabe que va a morir, que es un ser para la muerte, no solo que muere, sino que conoce, que tiene la certeza de que va a morir. A pesar de la infinitud de posibilidades de su futuro, la única posibilidad que está presente siempre en todas las posibilidades es la muerte. Sabe que un día va a morir. Ellacuría coincide con Heidegger cuando afirma que: "Entre los animales, el hombre es el único que puede percatarse de lo inalcanzable de sus acciones, de lo aventurado y vulnerable de sus proyectos, el único que se sabe sujeto a la enfermedad y abocado a la muerte"20 y por lo tanto un ser que tiene conciencia de lo efímero de su vida y de sus propósitos.

16. Ibid., 17.

17. Ignacio Ellacuría, «Existencialismo ateo», 636.

18. Ignacio Ellacuría, «Cinco lecciones de filosofía de Xavier Zubiri.», 196.

19. Martín Heidegger, Ser y tiempo, 231.

20. Ignacio Ellacuría, «Filosofía de la religión en Bergson», 342. 
El modo de ser del Dasein es ser en el mundo, y una de sus posibilidades es ser antes que realidad, posibilidad. Una cosa siempre será una cosa, pero el ser humano siempre está construyéndose, se desarrolla, es proyecto arrojado hacia el futuro. El ser humano es sus posibilidades; ellas lo constituyen, están ahí. Ellacuría al respecto dice:

El hombre y el mundo son, pues, dos entes heterogéneos, que, sin embargo, se ven obligados a unificarse para que el primero inserte su ser extranatural en el segundo. En esto precisamente va a consistir la existencia humana. El hombre no es el mundo, pero el mundo le es necesario al hombre. ${ }^{21}$

En esta afirmación se constata la relación entre el hombre y el mundo, ambos necesarios para que se desarrolle la existencia humana, donde el primero es visto como una base material para que el segundo construya su proyecto.

Para Heidegger, el hombre común se pasa la vida ocultándose (Adán luego de la caída) y tratando de que le oculten su realidad, de que es un ser mortal. El término que usa Heidegger para identificar al ser cotidiano es das Man. El das Man se escapa, quiere fugarse de la realidad que implica la mortalidad y busca un espacio, un lugar que adormezca la posibilidad de la muerte, porque no quiere morir. El Dasein es la realidad humana, no tiene género, es ese ser que va a morir y para negar esta realidad que le angustia y le desespera, se entrega a la existencia inauténtica. Heidegger plantea que la vida inauténtica es negar que el hombre es ese ser que va a morir:

La indagación dirigida hacia el fenómeno que permite responder a la pregunta por el quién, conduce hacia estructuras del Dasein que son co-originarias con el estar-en-el-mundo: el coestar [Mitsein] y la coexistencia [Mitdasein]. En este modo de ser se funda el modo cotidiano de ser-sí-mismo, cuya explicación hace visible eso que podemos llamar el "sujeto" de la cotidianidad: el "se" o el "uno" [das Man].22

Heidegger plantea que la vida inauténtica es la negación de que el hombre es ese ser que va a morir. Lo constitutivo el Dasein es estar en el mundo como caído, como arrojado, y en la cotidianidad de estar en el mundo se pierde, se escurre, dejando de lado la posibilidad de constituirse a sí mismo, de ser, porque ha caído en el mundo. Esta caída en el mundo implica una resolución: debe buscar la posibilidad de ser sí mismo. Y eso lo angustia porque no logra ser el que debe ser, por eso toma la resolución de cargar con su ser: 
El adelantarse le revela al Dasein su pérdida en el 'uno mismo' y lo conduce ante la posibilidad de ser sí mismo sin el apoyo primario de la solicitud ocupada, y de serlo en una libertad apasionada, libre de las ilusiones del uno, libertad fáctica, cierta de sí misma y acosada por la angustia: la libertad para la muerte ${ }^{23}$

Ellacuría también aborda la situación del hombre en medio del mundo y plantea que:

\begin{abstract}
El hombre se nos presenta, por lo pronto, como una realidad viviente, cuya actividad vital tiene dos vertientes: una da a las cosas que le suscitan, le afectan y a las que da respuestas, mientras que la otra da a sí mismo, de modo que el viviente en su comportamiento con las cosas y aun consigo mismo se dirige hacia sí y se autoposee con cierta independencia del medio y con cierto control sobre él. ${ }^{24}$
\end{abstract}

Pero este hombre no puede quedarse estático, inactivo, sino que ha de realizarse y para ello debe adoptar una actitud de apertura frente a la realidad y "por estar abierto a su propio carácter de realidad (...) no solo se hace a sí mismo, sino que hace su propio carácter de realidad ${ }^{25}$, de ahí que, al igual que su maestro, defina al hombre como el animal de realidades.

En otras palabras, la vida humana debe enfrentarse con la muerte y cargar consigo misma y solo ahí es cuando rompe con sus ataduras al mundo del 'uno mismo', y se libera de lo inauténtico; pero si deja que el entorno le diga que hacer, como ser; si se pierde en lo público, entre las habladurías, la curiosidad y la ambigüedad del ahí, entonces se convierte en el dasman, el espectador de la existencia, de lo que pasa, del que hace lo que se le dice, aquel que se camufla en el mundo de lo anónimo, en el mundo de lo uno. En este mundo, el hombre inauténtico se diluye, se funde en esa condición creyendo así que la muerte nunca le llegará. La posibilidad de todas las posibilidades es la realidad de la muerte, y afrontar la vida teniendo en cuenta esta realidad nos hace volver a la posibilidad de ser. "Amiga de la vida, compañera de camino, cuando te vea cara a cara, sabré que me has vencido"26

Heidegger considera que el ser humano es un yecto, es decir que está arrojado en el mundo y que su existencia hace posible su ser (Dasein) en la medida que permanezca abierto (libertad) lo que hace posible el proyecto. Dice Ellacuría citando a Heidegger "El hombre es lo que es por el ser, hasta tal punto que somos y existimos de tal manera que lo que se da principalmente, aún en nosotros, no es el hombre, sino el ser"27.

23. Ibid., 262

24. Ignacio Ellacuría, Filosofía de la realidad histórica, 248.

25. Ibid., 260.

26. Frase de un grupo inédito de poemas del autor de esta tesis.

27. Ignacio Ellacuría, «Existencialismo ateo», 637. 
Jean Paul Sartre nació en París (Francia) en 1905, fue filósofo, escritor y dramaturgo. Se auto consideraba existencialista y defendió también el materialismo humanista. (1945).

En su obra La Náusea (1938), aunque es una novela, el autor expone sus ideas filosóficas sobre la existencia, presentando al protagonista Roquentin, como aquel ser humano que experimenta la vida como algo repugnante que le provoca náusea debido al sin sentido que encuentra en la existencia. ¿Para qué existir? ¿Para qué vivir? El personaje descubre que la existencia es el mismo "Existir es estar ahí, simplemente; los existentes aparecen, se dejan encontrar, pero nunca es posible deducirlos... Todo es gratuito: ese jardín, esta ciudad, yo mismo"28

Sartre describe lo que es la náusea cuando pone en boca del protagonista la siguiente frase: "La Náusea no me ha abandonado y no creo que me abandone tan pronto; pero ya no la soporto, ya no es una enfermedad ni un acceso pasajero: soy yo". ${ }^{29}$ Se puede constatar en esta afirmación que la existencia es parte de él mismo, es decir, Roquentin se descubre como alguien que existe porque tiene la capacidad de darse cuenta de su existir, pero que la percibe como una enfermedad que permanece siempre presente, es decir, su existencia le causa vértigo debido a que también se enfrenta a la no existencia, a la nada:

Yo soy mi pensamiento, por eso no puedo detenerme. Existo porque pienso... y no puedo dejar de pensar. En este mismo momento -es atrozsi existo es porque me horroriza existir. Yo, yo me saco de la nada a la que aspiro; el odio, el asco de existir son otras tantas maneras de hacerme existir, de hundirme en la existencia. ${ }^{30}$

El término angustia es abordado por Sartre como telón de fondo en su novela. Roquentin experimenta la angustia traducida como nausea, porque la existencia lo coloca frente a la vida y a las decisiones que tiene que tomar para seguir vivo o viviendo. Se presenta a la angustia como el estado al que llega o que siempre ha estado el existente que debe darle sentido a su existencia. Elegir provoca angustia.

Posteriormente en El Ser y la Nada (1943), Sartre retoma el problema que ya Heidegger había abordado, ¿Por qué es el ser y no la nada? Entonces analiza el ser y la nada afirmando que el ser es y no necesita de la nada para concebirse. Pero como concibe la nada: "si la Nada no puede concebirse ni fuera del Ser ni a partir del Ser y si, por otra parte, siendo no-ser, no puede sacar de sí misma la fuerza necesaria para «nihilizarse», la Nada ¿de dónde viene?" ${ }^{31}$ Concluye que la nada necesita de un ser que sea capaz de nihilizarla: "el hombre es el ser a través del cual la nada viene al mundo"32

\footnotetext{
28. Jean Paul Sartre, La náusea.

29. Ibid., 105.

30. Ibid., 82.

31. Jean Paul Sartre, El ser y la nada, 58.

32. Ibid., 60.
} 
Propone entonces la distinción de dos tipos de ser: el ser en sí y el ser para sí. Cuando expone que es el ser en sí, señala que el ser en sí es algo diferente de la conciencia; la conciencia es intencional, es conciencia de algo, y ese algo no es conciencia, es lo que Sartre llama ser en sí. La conciencia en cambio es el ser para sí. Aquí se presenta la necesidad de clarificar los términos pues: “El ser es. El ser es en sí. El ser es lo que es" 33 a diferencia del ser para sí que se define "como el que es lo que no es y el que no es lo que es" ${ }^{34}$, es decir proyecto. Ellacuría coincide con Sartre en aquello cuando expresa que: "El hombre, en efecto, es fundamentalmente un pro-yecto. Proyecto porque está sin hacer y ha de hacerse; proyecto porque está arrojado hacia un futuro que depende de su decisión y que, por lo tanto, es creación suya"35

Al existencialismo se lo acusa de ser una teoría materialista, quietista y pesimista, Sartre en su obra El existencialismo es un humanismo (1945), plantea que por el contrario, el existencialista mira a la vida con optimismo, pero centrado en lo que el hombre se decida ser y hacer:

El hombre es el único que no sólo es tal como él se concibe, sino tal como él se quiere, y como se concibe después de la existencia, como se quiere después de este impulso hacia la existencia; el hombre no es otra cosa que lo que él se hace. ${ }^{36}$

El ser humano es un proyecto que tiene que construirse permanentemente, es el ser para sí que no está acabado, que en cada momento de su existencia, y en eso consiste su existencia, tiene que hacerse porque es responsable de su existencia y además porque es consciente de que existe. En este sentido Sartre plantea que la existencia precede a la esencia y el tomar a cargo la propia existencia para nada es un planteamiento pesimista, al contrario, es una teoría optimista porque no considera la existencia un determinismo sino que el ser humano puede buscar el sentido de su vida en el hacer de su existencia una respuesta al sin sentido, ante lo cual Ellacuría dice que: "Proyecto es tan sólo el hombre, porque lo que va a ser de él dependerá de su libertad, de lo que él quiera hacer de sí mismo". ${ }^{37}$

El existencialismo no raya en ser una propuesta subjetivista en extremis. El existencialista funda su certeza en el cogito pero a diferencia de Descartes no propone fundamentar una subjetividad absoluta, sino que plantea que la verdad fundada en el cogito le permite a la persona descubrirse a sí misma distinta de las cosas, y descubrir al otro y los otros como personas. Por lo tanto, el existencialismo se convierte así en un humanismo que da una dignidad al hombre, y no es un materialismo que lo convierte en un objeto, pues aunque resalta la existencia del

33. Ibid., 32.

34. Ibid., 34-35.

35. Ignacio Ellacuría, «Existencialismo ateo», 629.

36. Jean Paul Sartre, El existencialismo es un humanismo, 11-12.

37. Ignacio Ellacuría, «Existencialismo ateo», 629. 
sujeto individual, esa misma subjetividad no se entiende sino comprometido en la existencia de los otros.

Por el yo pienso, contrariamente a la filosofía de Descartes, contrariamente a la filosofía de Kant, nos captamos a nosotros mismos frente al otro, y el otro es tan cierto para nosotros como nosotros mismos. Así, el hombre que se capta directamente por el cogito, descubre también a todos los otros y los descubre como la condición de su existencia. ${ }^{38}$

Sartre considera que el hombre es angustia porque tiene que elegir libremente y eso implica compromiso consigo mismo y con la humanidad entera ya que al elegir no solo se elige a sí mismo sino a toda la humanidad en él representada.

Ante todo ¿qué se entiende por angustia? El existencialista suele declarar que el hombre es angustia. Esto significa que el hombre que se compromete y que se da cuenta de que es no solo el que elige ser, sino también un legislador, que elige al mismo tiempo que a sí mismo a la humanidad entera. ${ }^{39}$

Esta es una gran responsabilidad ante la cual el ser humano no puede permanecer pasivo. La angustia no impide obrar al hombre que elige, pues está inmersa en el mismo obrar del ser humano, porque el hombre es libre para decidir, y en la misma decisión se encuentra presente la angustia, por lo tanto el existencialismo no es una teoría que promueva el quietismo. ${ }^{40}$

Ellacuría cuando habla de Sartre, reconoce que para el filósofo francés el hombre "es un ser abierto, un ser trascendente; abierto en y a la trascendencia, en el sentido mismo en que es existencia y libertad" ${ }^{41}$ por lo tanto, esta apertura le conduce al encuentro con el otro, con los demás, y con el Otro, porque "el hombre es proyecto, proyección fuera de sí hacia un más allá en el que está su futuro y su realización profunda." ${ }^{\prime 2}$

El existencialismo ateo de Sartre considera la no existencia de Dios, y eso provoca que el ser humano tome conciencia de que está solo, y por ello el hombre está condenado a ser libre; “condenado, porque no se ha creado a sí mismo, y sin embargo, por otro lado, libre, porque una vez arrojado al mundo es responsable de todo lo que hace"43. Es el hombre el que debe asumir su existencia libremente y su estar en el mundo le obliga a crear, a construirlo, por lo tanto, a inventar los valores, por cuanto los valores metafísicos radicados en la divinidad ya no están: Y, además, decir que nosotros inventamos los valores no significa más que esto: la vida, a priori, no tiene sentido. Antes de que ustedes vivan, la vida no es nada;

38. Jean Paul Sartre, El existencialismo es un humanismo, 26.

39. Jean Paul Sartre, El existencialismo es un humanismo.

40. Cfr. Ibid., 13-15.

41. Ignacio Ellacuría, «Existencialismo ateo», 631.

42. Ibid.

43. Jean Paul Sartre, El existencialismo es un humanismo, 17. 
les corresponde a ustedes darle un sentido, y el valor no es otra cosa que este sentido que ustedes eligen. ${ }^{44}$

La gran responsabilidad que tiene el ser humano frente a sí mismo, a los demás y al mundo es tremenda y de vital importancia, pues allí es donde pone en juego su libertad para darle sentido a la historia, a su historia, a su proyecto.

\section{Conclusión}

Ellacuría construye su filosofía con los elementos filosóficos propios de su momento histórico ya que intenta sintetizar lo antiguo y lo moderno. Se siente insatisfecho por el aporte escolástico ya que lo considera demasiado dogmático y especulativo. Se siente atraído por el pensamiento existencialista, por cuanto aborda la problemática existencial del hombre contemporáneo, pero se mantiene distante de los planteamientos ateos de Sartre y agnóstico de Heidegger por su crítica a la metafísica.

En esta investigación se puede apreciar que la pregunta es muy natural en el ser humano y la pregunta por el sentido de la vida mucho más porque es el único ser que se cuestiona por su existencia. Es gracias al Dasein (el hombre) que la pregunta es posible; según los existencialistas, es ese ser-ahí, arrojado en el mundo el que es un ser-para-sí, diferente del ser-en-sí que no cambia, es decir es un ser en proyecto porque es lo que no es y no es lo que es. Si el ser humano tiene que hacerse la vida con lo que en el mundo le da, entonces Ellacuría propone que el ser humano es histórico pues es él quien escribe su propia biografía.

La vida misma es el fundamento de la existencia y no la metafísica entendida como el mundo de las ideas, de la razón. La vida se convierte en la realidad para el hombre, que debe acrecentarla, que debe vivirla de manera total, asumiendo la historia, su propia historia para construirla de manera responsable, porque "el hombre es lo que hace con lo que hicieron de él" en palabras de Sartre y por lo tanto debe hacerse cargo de la realidad, cargar con ella y encargarse de esa realidad de manera libre y responsable según Ellacuría.

La angustia que experimenta el ser humano ante lo incierto, es la que le permite tomar conciencia de su existencia y con ella de la libertad que le es propia, pues debe decidir, elegir que hacer, ya que su vida no está definida, acabada, debe construirla, porque el hombre es libre para hacer historia con su historia.

Ellacuría como creyente reconoce en el ser humano su existencia como proyecto, como ser libre, como historia, pero parte del hecho de que el hombre es una creatura de Dios, y es Él quien le da el ser, pero un ser que es histórico, donde ese ser se puede realizar de distintos modos, pues es un ser libre capaz de liberarse del curso obligante de la naturaleza y capaz, entre ciertos límites, de hacerse la existencia que acepte como suya. ${ }^{45}$ 


\section{BIBLIOGRAFIA}

Albert Camus. El mito de Sísifo. Tercera. Madrid: Alianza Editorial, 1985. Francis Fernandez. «Sartre y el sentido de la vida». El independiente de Granada. 23 de abril de 2017.

Ignacio Ellacuría. «Cinco lecciones de filosofía de Xavier Zubiri.» En Escritos filosóficos, Primera., II:664. San Salvador: UCA Editores, 1999. «Correspondencia con Ángel Martínez». En Escritos Filosóficos, Primera., 1:644. San Salvador: UCA Editores, 1996.

«Existencialismo ateo». En Escritos filosóficos, Vol. 1. San Salvador: UCA Editores, 1996.

Filosofía de la realidad histórica. Madrid: Editorial Trotta, 1991.

«Filosofía de la religión en Bergson». En Escritos filosóficos, Primera., I:644. San Salvador: UCA Editores, 1996.

«Sobre la irreligiosidad». En Escritos filosóficos, 1.a ed., 1:644. San Salvador: UCA Editores, 1996.

«Técnica y vida humana». En Escritos filosóficos, Primera., I:644. San Salvador: UCA Editores, 1996.

Jean Paul Sartre. El existencialismo es un humanismo. 2da edición. México: Grupo Editorial Tomo S.A., 2014.

---. El ser y la nada. Barcelona: Altaya S.A., 1993.

---. La náusea. 9na ed. México: Época S.A., s. f. http://www.infojur.ufsc. br/aires/arquivos/Jean\%20Paul\%20Sartre\%20-\%20La\%20Nausea.pdf.

Martín Heidegger. Ser y tiempo, s. f. https://espanol.free-ebooks.net/ ebook/Ser-y-el-Tiempo.

OMS. «Datos y cifras sobre el suicidio: infografía». Organización Mundial de la Salud, s. f. http://www.who.int/mental_health/suicide-prevention/ infographic/es/.

Soren Kierkegaard. «El concepto de la angustia». En Escritos Soren Kierkegaard, 4/2:360. Madrid: Trotta, 2016.

Temor y temblor Madrid: Editora Nacional, 1975

Estética y ética en la formación de la personalidad. España: Espuela de plata, 2007. 